\title{
The effects of adjuvant intrathecal fentanyl on postoperative pain and rebound pain for anorectal surgery under saddle anesthesia
}

\author{
Sung-Min Shim, Jae-Ho Park, Dong-Min Hyun, Eui-Kyun Jeong, \\ Seong-Su Kim, and Hwa-Mi Lee \\ Department of Anesthesiology and Pain Medicine, Gangneung Asan Hospital, University of Ulsan College of \\ Medicine, Gangneung, Korea
}

\begin{abstract}
Background: Intrathecal opioid has been known to enhance the quality and prolong the duration of spinal anesthesia, as well as to reduce postoperative pain. The purpose of this study was to evaluate postoperative analgesic characteristics of intrathecal fentanyl for the first 48 hours after anorectal surgery under saddle anesthesia.

Methods: Eighty patients were recruited in our study. Forty patients were randomly allocated to group B that received $0.5 \%$ bupivacaine $5 \mathrm{mg}$ with $0.3 \mathrm{ml}$ normal saline. The other 40 patients were assigned to group $\mathrm{BF}$ which was given $0.5 \%$ bupivacaine $5 \mathrm{mg}$ with fentanyl $15 \mu \mathrm{g}$. The primary outcome variable was a numeric rating scale (NRS) at six hours postoperatively. Secondary outcomes included changes in the NRS score between one and 48 hours postoperatively, consumption of rescue analgesics, and the frequency of rebound pain.

Results: Group BF exhibited a lower mean NRS score at postoperative six hours compared to group B $(\mathrm{P}<0.001)$. However, the mean NRS score was not different after postoperative six hours between the two groups. The median consumption of rescue analgesics in group $\mathrm{BF}$ was less than that of group $\mathrm{B}(\mathrm{P}=0.028)$ and the frequency of rebound pain decreased in group $\mathrm{BF}$ when compared to group $\mathrm{B}(\mathrm{P}=0.021)$. The levels of sensory block were $\mathrm{S} 1$ dermatome and motor block scores were 0 for both groups. There was no significant difference in adverse effects between the groups.

Conclusions: Intrathecal fentanyl $15 \mu \mathrm{g}$ for anorectal surgery under saddle anesthesia led to an improved pain score for the first six hours after surgery and decreased postoperative analgesic use. Rebound pain diminished with intrathecal fentanyl and adverse effects did not increase.
\end{abstract}

Keywords: Anorectal surgery; Bupivacaine; Intrathecal fentanyl; Saddle anesthesia.

Corresponding author: Hwa-Mi Lee, M.D.

Department of Anesthesiology and Pain Medicine, Gangneung Asan Hospital, University of Ulsan College of Medicine, 38, Bangdong-gil, Sacheon-myeon, Gangneung 25440, Korea

Tel: 82-33-610-3409, Fax: 82-33-641-8180

Email: parousia77@naver.com

ORCID: https://orcid.org/0000-0002-1919-5528

Received: April 14, 2017.

Revised: June 20, 2017 (1st); July 24, 2017 (2nd).

Accepted: July 28, 2017.

Korean J Anesthesiol 2018 June 71(3): 213-219

https://doi.org/10.4097/kja.d.18.27097

\section{Introduction}

Pain management of surgery not only relieves patients' pain, but also plays an important role in preventing complications after an operation. Postoperative pain is said to be most severe in anorectal surgery [1] and thus, the choice of anesthetic methods in this procedure is crucial to reduce aches as well as postoperative complications.

Anesthetic methods of anorectal surgery such as hemorrhoidectomy, fistulotomy, incision and drainage of perianal abscess vary, for example in the use of local infiltration, spinal

(c) This is an open-access article distributed under the terms of the Creative Commons Attribution Non-Commercial License (http://creativecommons.org/ licenses/by-nc/4.0/), which permits unrestricted non-commercial use, distribution, and reproduction in any medium, provided the original work is properly cited. 
anesthesia, caudal anesthesia, or general anesthesia [2-5]. Among them, spinal anesthesia is commonly used for anorectal surgery which does not need a sophisticated machine and which has been performed for years before anesthetic equipment such as mechanical ventilators and monitoring devices was produced. The development of new local anesthetic agents, the use of opioids, and an interest in acute and chronic pain management have universalized spinal anesthesia.

Immediate pain is very severe in anorectal surgery and difficult to control with intravenous analgesics alone. Moreover, due to the short hospitalization period, there is a limit in the application of patient-controlled analgesia that permits patients to treat pain by directly activating doses of intravenous narcotics. Intrathecal fentanyl has been used relatively frequently in Cesarean sections, lower extremity surgery, urology, and ambulatory day surgery since it is well known that this opioid's onset time is quite speedy, sensory and motor blocks are definitive, and the use of local anesthetics can be reduced [6-9]. However, the application of fentanyl in anorectal surgery is rare: Neither the incidence and quality of pain nor pain control have been studied yet.

Therefore, this study was designed to explore whether postoperative pain in anorectal surgery and rescue analgesics' consumption can be reduced by including intrathecal fentanyl for the first 48 hours after surgery under saddle anesthesia. We also investigated its association with the results of saddle anesthesia and adverse effects.

\section{Materials and Methods}

\section{Study population}

This study was approved by the Institutional Review Board of our institution (IRB Number 2016-05-003). It followed ethical considerations in the Declaration of Helsinki. Written informed consent was obtained from all patients before surgery. Between May 2016 and January 2017, 86 patients scheduled for anorectal surgery between $8 \mathrm{a} . \mathrm{m}$. and $10 \mathrm{a} . \mathrm{m}$. at our institution were enrolled in this study. Subjects with the followings were excluded from the study, such as contraindications to regional anesthesia, an age of less than 19 years, or the American Society of Anesthesiologists (ASA) class III or higher.

\section{Randomization}

Patients were randomly assigned to one of two groups by a computer-generated random number table. Group B received $0.5 \%$ bupivacaine $5 \mathrm{mg}$ with normal saline $0.3 \mathrm{ml}$ and group $\mathrm{BF}$ $0.5 \%$ bupivacaine $5 \mathrm{mg}$ with fentanyl $15 \mu \mathrm{g}(0.3 \mathrm{ml})$. The total volume of $1.3 \mathrm{ml}$ was equal for both groups.
Double-blind randomization was performed by computergenerated allocation (www.psychicscience.org/random.aspx). A selected nurse who was not participated in anesthetic induction opened the group assignment envelope and prepared a syringe. An anesthesiologist performed spinal anesthesia and collected the data.

\section{Anesthetic management}

None of the patients received premedication. The intravenous lines were inserted at the wards. When the subjects arrived at the operating room, lactated Ringer's solution $5 \mathrm{ml} / \mathrm{kg}$ was infused for pre-hydration in the supine position. Electrocardiography, non-invasive blood pressure monitoring, and pulse oximetry were employed for monitoring and the vital signs recorded every 5 minutes.

Patients sat at the operating bed and the skin was prepared with a povidone-iodine solution. Spinal anesthesia was performed at either the L3-L4 or L4-L5 interspace through a midline approach using a 25-gauge Quincke needle (Tae-Chang Industrial Co., Ltd., Korea). After verification that the cerebrospinal fluid was freely flowing from the hub, the hole of the spinal needle was pointed downwards, and then agents injected for about 10 seconds following gentle aspiration. After the injection, the patients sat for 10 minutes and then moved to a Jack-knife position.

Postoperatively, all of the patients were ordered to stay in bed for six hours.

Patients received codeine $10 \mathrm{mg} /$ ibuprofen $200 \mathrm{mg} /$ acetaminophen $250 \mathrm{mg}$ orally three times a day beginning with the next day after surgery. An intravenous rescue analgesic was prohibited until six postoperative hours. Tramadol $50 \mathrm{mg}$ was given if the NRS score was more than 4 after six postoperative hours.

\section{Data collection}

An anesthesiologist recorded the anesthetic data and vital signs. Levels of sensory and motor blocks were checked immediately before the Jack-knife position. The sensory level was examined by cold perception using alcohol-soaked gauze and the motor block level by a modified Bromage scale ( 0 , no motor block; 1, can flex knee, move foot, but cannot raise leg; 2, can move foot only; 3 , cannot move foot or knee). Adverse effects due to spinal anesthesia such as hypotension, bradycardia, nausea, vomiting, and pruritus were recorded during surgery, at the post-anesthesia care unit, and in the general wards.

Hypotension was defined as a decrease in systolic pressure by $20 \%$ from the blood pressure before the spinal anesthesia and lower than $100 \mathrm{mmHg}$. Ephedrine $5 \mathrm{mg}$ was injected in case of hypotension. Bradycardia was defined as a heart rate of less than 
50 beats/min and treated with glycopyrrolate $0.2 \mathrm{mg}$.

\section{Outcome evaluation}

The numeric rating scale (NRS) pain score, urinary retention, and adverse effects were checked postoperatively after 2 , $4,6,8,10,18,24,36$, and 48 hours. The NRS pain score ranged from 0 (no pain) to 10 (the most severe pain that the patient had ever experienced) and the primary outcome variable was the NRS score at six hours postoperatively. Secondary outcome variables included NRS changes between one and 48 hours postoperatively, rescue analgesic consumption, and the frequency of rebound pain. The total consumption of rescue analgesics was counted from six to 48 hours postoperatively. An NRS elevation after reaching the maximal NRS score between one and 48 hours post-surgically during a decrease in pain was defined as rebound pain.

\section{Statistical analysis}

In a preliminary study, the difference of the mean NRS score at six hours postoperatively between intrathecal fentanyl $15 \mu \mathrm{g}$ group and no intrathecal fentanyl group was 1.6. The sample size of 39 patients in each group was calculated to obtain $90 \%$ statistical power and an $\alpha$ error of 0.05 . The final sample size consisted of 86 patients to allow for a $10 \%$ attrition rate.

All results were expressed as the mean \pm standard deviations, median (range), or number (percentage). Adverse effects were described by the number of patients. Demographic data were analyzed with student's $t$ test (age, weight, and height) and Chisquare test (gender and ASA). Fisher's exact test was used to examine contingency tables such as for operation types and adverse effects of saddle anesthesia. The saddle anesthesia data were examined by student's $t$ test. Repeated-measures ANOVAs and Bonferroni's test were calculated for the NRS pain score with an adjusted $\mathrm{P}$ value $<0.005$ considered to be significant. Pain medications and rescue analgesics were examined with the Mann-Whitney $U$ test. A univariate logistic regression was conducted for predictors of rebound pain. Statistical analyses were performed using SPSS Statistics version 23 (IBM Corp., USA). P values $<0.05$ were considered to be statistically significant.

\section{Results}

\section{Patient enrollment and study population (Fig. 1 and Table 1)}

Eighty six patients were enrolled in our study. Three patients were excluded because one of them rejected saddle anesthesia due to fear and anxiety and two refused to participate. In the

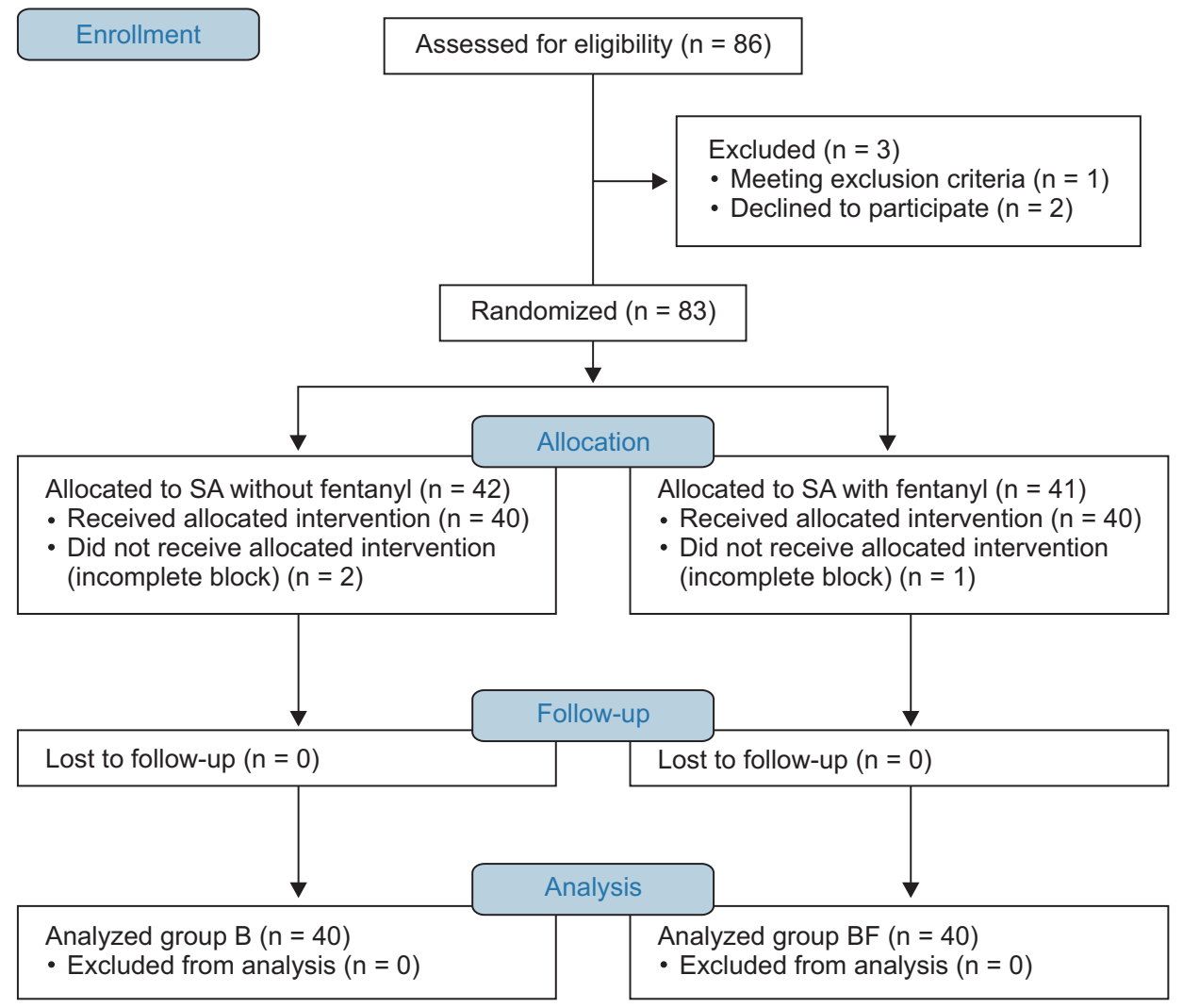

Fig. 1. CONSORT flow diagram. SA: saddle anesthesia. 
Table 1. Patients' Characteristics

\begin{tabular}{lccc}
\hline \multicolumn{1}{c}{ Factors } & $\begin{array}{c}\text { Group B } \\
(\mathrm{n}=40)\end{array}$ & $\begin{array}{c}\text { Group BF } \\
(\mathrm{n}=40)\end{array}$ & P value \\
\hline Age $(\mathrm{yr})$ & $46.3 \pm 14.0$ & $48.7 \pm 12.7$ & 0.430 \\
Weight $(\mathrm{kg})$ & $63.8 \pm 13.3$ & $67.9 \pm 11.6$ & 0.150 \\
Height $(\mathrm{cm})$ & $163.2 \pm 8.9$ & $163.4 \pm 8.7$ & 0.930 \\
Gender & & & 0.820 \\
$\quad$ Male & 18 & 17 & \\
$\quad$ Female & 22 & 23 & \\
ASA PS & & & 0.823 \\
$\quad$ I & 21 & 20 & \\
$\quad$ II & 19 & 20 & \\
Operation type & & & \\
$\quad$ Hemorrhoidectomy & 33 & 30 & \\
$\quad$ Fistulotomy & 4 & 7 & \\
Incision and drainage* & 3 & 3 & \\
\hline
\end{tabular}

Values are the mean \pm SD or number of patients. Group B without intrathecal fentanyl, Group BF with intrathecal fentany. ASA PS: American Society of Anesthesiologists Physical Status. *Incision and drainage were performed for perianal abscess.

Table 3. Adverse Effects of Saddle Anesthesia

\begin{tabular}{lccc}
\hline \multicolumn{1}{c}{ Factors } & $\begin{array}{c}\text { Group B } \\
(\mathrm{n}=40)\end{array}$ & $\begin{array}{c}\text { Group BF } \\
(\mathrm{n}=40)\end{array}$ & P value \\
\hline Respiratory difficulty $^{*}$ & 0 & 0 & NS \\
Hypotension $^{\dagger}$ & 0 & 0 & NS \\
Bradycardia $^{*}$ & 0 & 0 & NS \\
Nausea/vomiting $_{\text {Dizziness/headache }}$ & 1 & 0 & 1.000 \\
Movement/pain in surgery $_{\text {Pruritus }}$ & 0 & 5 & 0.712 \\
Back pain $_{\text {Urinary retention }}{ }^{\S}$ & 0 & 0 & NS \\
\end{tabular}

Values are the number of patients. Group B without intrathecal fentanyl, Group BF with intrathecal fentanyl. NS: not significant. * Respiratory difficulty, $<\mathrm{SpO}_{2} 90 \%$. ${ }^{\dagger}$ Hypotension, decrease in systolic pressure by $20 \%$ less than baseline or lower than $100 \mathrm{mmHg}$. ${ }^{\ddagger}$ Bradycardia, heart rate less than 50 beats $/$ min. ${ }^{8}$ Urinary retention, urine removed by Nelaton catheter.

end, 83 patients were included in this study. Among them, 42 patients belonged to group $\mathrm{B}$ and 41 to group $\mathrm{BF}$. Two subjects in group $\mathrm{B}$ and one in group $\mathrm{BF}$ were excluded because of incomplete block, and they were anesthetized two times (Fig. 1).

There were no statistical differences between the two groups with regard to the demographic data (Table 1).

\section{Result of saddle anesthesia (Table 2)}

Levels of sensory block were S1 and levels of motor block were 0 on the modified Bromage scale for both groups. There were also no statistical differences in operating time. No subject felt pain during the operation and no one had to be converted to
Table 2. Results of Saddle Anesthesia

\begin{tabular}{lccc}
\hline \multicolumn{1}{c}{ Factors } & $\begin{array}{c}\text { Group B } \\
(\mathrm{n}=40)\end{array}$ & $\begin{array}{c}\text { Group BF } \\
(\mathrm{n}=40)\end{array}$ & P value \\
\hline Level of sensory block & $\mathrm{S} 1$ & $\mathrm{~S} 1$ & $\mathrm{NS}$ \\
Motor block score* & 0 & 0 & $\mathrm{NS}$ \\
Operating time (min) & $41.5 \pm 9.8$ & $43.6 \pm 15.0$ & 0.474 \\
Inotropic use & 0 & 0 & NS \\
Pain during operation & 0 & 0 & NS \\
Conversion to general anesthesia & 0 & 0 & NS \\
\hline
\end{tabular}

Values are the mean \pm SD and number of patients. Group B without intrathecal fentanyl, Group BF with intrathecal fentanyl. * Modified Bromage scale ("0" means there is no motor block).

general anesthesia (Table 2).

\section{Adverse effects (Table 3)}

There were no significant differences regarding adverse effects in the number of patients experiencing respiratory depression, bradycardia, hypotension, nausea, and vomiting. However, three out of eight patients (two in group B and one in group $\mathrm{BF}$ ) who expressed headache were diagnosed with post-dural puncture headache (PDPH) and an autologous epidural blood patch was performed. One group-B patient and two group-BF patients complained of back pain which resolved with conservative treatment. Two patients of group BF reported pruritus, but no medication was required (Table 3 ).

Catheterization for urinary retention was not statistically different between the two groups $(\mathrm{P}=0.822)$.

\section{Pain medication for a rescue analgesic}

A rescue analgesic (Tramadol) in the median amount of 46.0 $\mathrm{mg}$ was administered to group B and $34.9 \mathrm{mg}$ to group BF between six and 48 hours postoperatively, and this difference was statistically significant between the two groups $(\mathrm{P}=0.028)$.

\section{Pain scores and rebound pain (Fig. 2 and Table 4)}

Group BF showed a lower mean NRS score at postoperative two, four, and six hours compared to group B (0.0 vs. 1.0, 0.1 vs. 3.2 and 1.8 vs. 3.8 , respectively, $\mathrm{P}<0.001)$. However, there was no difference between six and 48 hours after surgery (Fig. 2).

Twenty patients in group B and 10 patients in group BF exhibited rebound pain. The frequency of rebound pain decreased in group $\mathrm{BF}$ compared to group $\mathrm{B}(\mathrm{P}=0.021)$. A univariate logistic regression analysis was performed with age, gender, height, ASA, intrathecal fentanyl, operation time, and operation type as independent variables (Table 4). Only intrathecal fentanyl was predictive of a lower rebound pain frequency $(\mathrm{P}=$ 


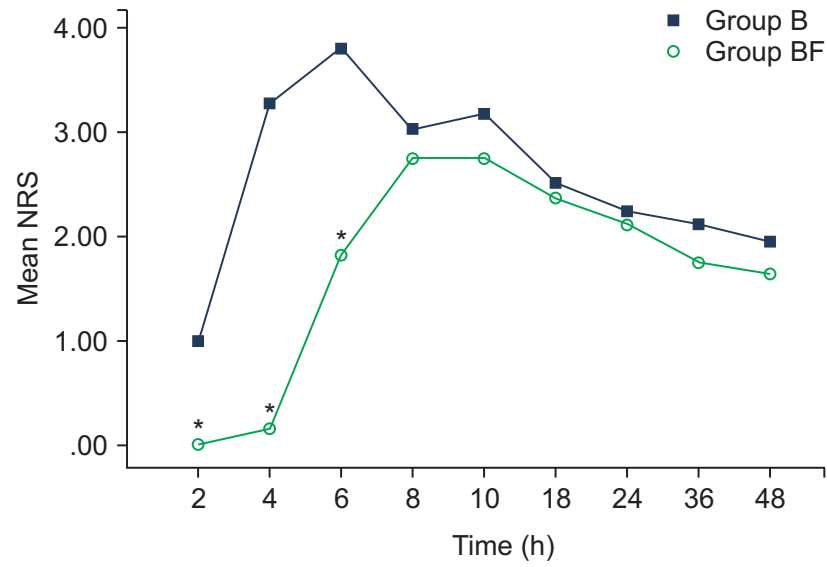

Fig. 2. Numeric rating scale (NRS) pain score according to postoperative time. Group B without intrathecal fentanyl. Group BF with intrathecal fentanyl. Adjusted P value, $0.05 / 9=0.005$. The asterisks $\left({ }^{*}\right)$ indicate statistically significant differences between the two groups $(\mathrm{P}<$ $0.001)$.

0.024 , odds ratio $=0.3$ )

\section{Discussion}

Anorectal disorders are the second most frequent disease by main surgery according to the 2015 statistical yearbook of the National Health Insurance Service in Korea [10]. Anorectal surgery is also associated with the most severe pain among all operations [1]. Thus, pain management is one of the crucial parts for appropriate postoperative patient care [11]. The effects of postoperative pain management include early ambulation and the reduction of adverse effects. The most common causes of delay for discharge are pain, drowsiness, and nausea or vomiting [12]. Therefore, an optimal anesthetic method should provide for excellent operating conditions, rapid recovery, fewer postoperative side effects, and high patient satisfaction. Spinal anesthesia is the most widespread anesthetic method. Addition of intrathecal opioid has been established for postoperative pain reduction, but it is unknown whether it is effective in anorectal surgery under saddle anesthesia.

Fentanyl is the most studied and most commonly used opioid that is delivered intrathecally. There are two trends of its use. First, analgesic effects can be taken advantage of in labor, delivery, and post-Cesarean delivery. Second, fentanyl provides a more rapid onset and a better surgical block, further contributing to rapid recovery and early discharge [13].

Shende et al. [14] stated that adding $15 \mu$ g fentanyl to bupivacaine for spinal anesthesia considerably enhanced surgical anesthesia for a Cesarean section. Choi et al. [15] reported that bupivacaine $12 \mathrm{mg}$ was the optimal dose for surgical anesthesia, but that it could be reduced to $8 \mathrm{mg}$ for Cesarean delivery with
Table 4. Predictors of Rebound Pain in a Univariate Logistic Regression

\begin{tabular}{lccc}
\hline \multicolumn{1}{c}{ Factors } & P value & Odds ratio & $\begin{array}{c}95 \% \mathrm{CI} \\
\text { for the odds ratio }\end{array}$ \\
\hline Age & 0.774 & 1.0 & $1.0-1.1$ \\
Gender & 0.850 & 0.2 & $0.0-1.2$ \\
Height & 0.050 & 1.1 & $1.0-1.3$ \\
Weight & 0.690 & 1.0 & $1.0-1.1$ \\
ASA PS & 0.605 & 1.4 & $0.4-4.8$ \\
Intrathecal fentanyl & 0.024 & 0.3 & $0.1-0.8$ \\
Operation time & 0.070 & 1.0 & $1.0-1.1$ \\
Operation type $(1)^{*}$ & 0.265 & 0.4 & $0.1-2.2$ \\
Operation type $(2)^{\dagger}$ & 0.262 & 0.2 & $0.0-3.0$ \\
\hline
\end{tabular}

Univariate predictors with $\mathrm{P}<0.05$. ASA PS: American Society of Anesthesiologists Physical Status. *Operation type (1) is fistulotomy versus hemorrhoidectomy. ${ }^{\dagger}$ Operation type (2) is incision and drainage versus hemorrhoidectomy.

$10 \mu$ g fentanyl. Similarly, Goel et al. [9] considered bupivacaine with fentanyl satisfactory for day surgery because it provided longer sensory anesthesia without delaying discharge.

In our study, no subject complained of pain during the operation and no one needed to be converted to general anesthesia. Saddle anesthesia with intrathecal fentanyl was satisfactory during the operation. The pain score of group BF was lower than of group B throughout six postoperative hours with no demonstrable benefits afterwards: Immediate postoperative pain was suppressed by intrathecal fentanyl but this did not extend after six hours. The mean NRS score of group B reached the maximal mean of 3.8 at six hours, decreased to 3.0 at eight hours, but increased again to 3.1 at 10 hours. However, the mean NRS score for the group BF was under 2.7 until 10 hours, did not increase afterwards, but continuously declined until 48 hours (Fig. 2). The maximal mean NRS score was reached at six and eight hours for the groups B and BF, respectively. Group B arrived at the maximal mean NRS score more quickly, which means that the pain in that subsample occurred more rapidly and was more severe than in group BF until six hours after surgery.

The total consumption of rescue analgesics for pain relief was less in group $\mathrm{B}$ than $\mathrm{BF}(\mathrm{P}=0.028)$ and the analgesic requirement was decreased by intrathecal fentanyl.

The most common disadvantage of intrathecal opioids is respiratory depression. Lipophilic opioids such as fentanyl have a narrow band of analgesia, even though the duration of pain relief is short. The analgesic band is limited to the lumbar dermatomes, so respiratory depression occurs less often [16]. However, hydrophilic opioids such as morphine possess a broad band of analgesia and have a slow onset with the pain-relieving duration of analgesia persisting for 18 to 24 hours, which is also the typical time span of monitoring after intrathecal morphine. Thus, morphine is useful as a long-acting analgesic, but the risk of life-threatening respiratory depression exists as the substance 
moves to the brain stem [17]. Lipophilic opioids are therefore used more frequently because patients can discharge shortly after surgery. Respiratory depression after more than two hours following their intrathecal delivery has never been reported.

We introduced rebound pain in this study and it has been occasionally employed for orthopedic surgery $[18,19]$. Rebound pain is so-called breakthrough pain and defined as the pain increase faced after the effects of local anesthetics wear off. Here, we defined that rebound pain is an increase in the pain score during decreasing pain after a maximal pain score has been reached. Intrathecal fentanyl diminished the frequency of rebound pain in our study $(\mathrm{P}=0.021)$ and predicted the low frequency of rebound pain occurring in a univariate logistic regression (Table 4). Intrathecal fentanyl is known to have a duration of about two to five hours [13]. However, we suppose that the remnant effect may last more than five hours or that immediate pain control during the first six hours could affect rebound pain after six hours. Hence, intrathecal fentanyl is effective for early postoperative pain and can decrease the occurrence of rebound pain when the block's effect disappears.

Adverse effects of spinal anesthesia such as hypotension, bradycardia, or respiratory difficulty did not occur in this study. Two group-BF patients (4.7\%) expressed pruritus, but there was no need for treatment and it was less common than in another investigation [7]. Eight patients complained of headaches and three patients (two in group $\mathrm{B}$ and one in group $\mathrm{BF}$ ) were confirmed as PDPH with an epidural blood patch applied whereas the other five cases could be resolved with conservative treatment. Urinary retention is a significant adverse effect of spinal anesthesia and associated with long-acting regional anesthetic blocks. The long hospital stay and the risk for urinary retention limit the use of intrathecal fentanyl in all patients [20]. Our study, however, showed that urinary retention did not increase with fentanyl.
This study had several limitations. First, pain scores such as those from the NRS are very subjective, even though the mean NRS difference between the two groups was statistically significant for the first six postoperative hours. Second, the anesthetized area was around the buttocks, perineum, and the thigh's inner surfaces which makes it difficult to locate the exact dermatome. Third, there was a problem in our study with regard to the modified Bromage scale because all patients had the same motor block. We need an alternative scale to evaluate the block level for saddle anesthesia. Fourth, there might have been an ethical problem regarding the absence of intravenous pain management for six hours despite the existence of pain. Fifth, we introduced rebound pain but the concept has not been commonly defined thus far, although proposed by a few studies in orthopedic surgery. Further research is needed to elucidate the nature of rebound pain.

Bupivacaine $5 \mathrm{mg}$ with fentanyl $15 \mu \mathrm{g}$ for anorectal surgery under saddle anesthesia showed an improved mean NRS score in the first six hours compared to bupivacaine $5 \mathrm{mg}$ with normal saline $0.3 \mathrm{ml}$. The group with fentanyl also exhibited decreased rebound pain. Pruritus that was a problem in most previous studies occurred less often in our research and instances of hypotension and bradycardia which are problems of spinal anesthesia did not show up. In conclusion, intrathecal fentanyl 15 $\mu \mathrm{g}$ is safe to use and provides satisfactory results for anorectal surgery under saddle anesthesia.

\section{ORCID}

Sung-Min Shim, https://orcid.org/0000-0001-7530-367X Hwa-Mi Lee, https://orcid.org/0000-0002-1919-5528 Eui-Kyun Jeong, https://orcid.org/0000-0002-6964-466X Seong-Su Kim, https://orcid.org/0000-0002-6817-7692

\section{References}

1. Famewo CE. Study of incidence of post-operative pain among Nigerian patients. Afr J Med Med Sci 1985; 14: 175-9.

2. Sun MY, Canete JJ, Friel JC, McDade J, Singla S, Paterson CA, et al. Combination propofol/ketamine is a safe and efficient anesthetic approach to anorectal surgery. Dis Colon Rectum 2006; 49: 1059-65.

3. Ye F, Feng YX, Lin JJ. A ropivacaine-lidocaine combination for caudal blockade in haemorrhoidectomy. J Int Med Res 2007; 35 : 307-13.

4. Li S, Coloma M, White PF, Watcha MF, Chiu JW, Li H, et al. Comparison of the costs and recovery profiles of three anesthetic techniques for ambulatory anorectal surgery. Anesthesiology 2000; 93: 1225-30.

5. Read TE, Henry SE, Hovis RM, Fleshman JW, Birnbaum EH, Caushaj PF, et al. Prospective evaluation of anesthetic technique for anorectal surgery. Dis Colon Rectum 2002; 45: 1553-8.

6. Choi DH, Ahn HJ, Chung IS. Spinal anesthesia for cesarean section: a comparison of three doses of hyperbaric bupivacaine and the effects of fentanyl. Korean J Anesthesiol 1999; 37: 37-44.

7. Lee SJ, Kim SH, Jung JD, Yoo BS, Lim KJ, So GY, et al. The effects of intrathecal fentanyl for spinal anesthesia in lower extremity surgery. Korean J Anesthesiol 2009; 56: 280-3.

8. Kim JE, Moon YE, Hong SH, Jeon JP, Chang HW, Kim SJ, et al. Comparison of clinical effect of intrathecally administered fentanyl for elderly 
patients undergoing urologic surgery. Korean J Anesthesiol 2008; 55: 579-84.

9. Goel S, Bhardwaj N, Grover VK. Intrathecal fentanyl added to intrathecal bupivacaine for day case surgery: a randomized study. Eur J Anaesthesiol 2003; 20: 294-7.

10. Main surgery statistical year book for 2015. Wonju: National Health Insurance Service in Korea; 2016 Feb. 531 p. Report NO.: 11-B550928000034-10. Available from http://www.nhis.or.kr/bbs7/boards/B0079/22272

11. Imani F. Postoperative pain management. Anesth Pain Med 2011; 1: 6-7.

12. Pavlin DJ, Rapp SE, Polissar NL, Malmgren JA, Koerschgen M, Keyes H. Factors affecting discharge time in adult outpatients. Anesth Analg 1998; 87: 816-26.

13. Rathmell JP, Lair TR, Nauman B. The role of intrathecal drugs in the treatment of acute pain. Anesth Analg 2005; 101(5 Suppl): S30-43.

14. Shende D, Cooper GM, Bowden MI. The influence of intrathecal fentanyl on the characteristics of subarachnoid block for caesarean section. Anaesthesia 1998; 53: 706-10.

15. Choi DH, Ahn HJ, Kim MH. Bupivacaine-sparing effect of fentanyl in spinal anesthesia for cesarean delivery. Reg Anesth Pain Med 2000; 25: 240-5.

16. Eisenach JC. Lipid soluble opioids do move in cerebrospinal fluid. Reg Anesth Pain Med 2001; 26: 296-7.

17. Samii K, Chauvin M, Viars P. Postoperative spinal analgesia with morphine. Br J Anaesth 1981; 53: 817-20.

18. Williams BA, Bottegal MT, Kentor ML, Irrgang JJ, Williams JP. Rebound pain scores as a function of femoral nerve block duration after anterior cruciate ligament reconstruction: retrospective analysis of a prospective, randomized clinical trial. Reg Anesth Pain Med 2007; 32: $186-92$.

19. DeMarco JR, Componovo R, Barfield WR, Liles L, Nietert P. Efficacy of augmenting a subacromial continuous-infusion pump with a preoperative interscalene block in outpatient arthroscopic shoulder surgery: a prospective, randomized, blinded, and placebo-controlled study. Arthroscopy 2011; 27: 603-10.

20. Gupta A, Axelsson K, Thörn SE, Matthiessen P, Larsson LG, Holmström B, et al. Low-dose bupivacaine plus fentanyl for spinal anesthesia during ambulatory inguinal herniorrhaphy: a comparison between $6 \mathrm{mg}$ and $7.5 \mathrm{mg}$ of bupivacaine. Acta Anaesthesiol Scand 2003; 47: 13-9. 